\title{
CCAT1: a pivotal oncogenic long non-coding RNA in human cancers
}

\author{
Yu Xin*, Zheng Li†, Jianxiong Shen $\dagger$, Matthew T. V. Chan $\ddagger$ and William Ka Kei Wuł§ \\ *Department of Dermatology, Peking Union Medical College Hospital, Chinese Academy of Medical Sciences and Peking Union Medical College, \\ Beijing 100042, China, †Department of Orthopedics Surgery, Peking Union Medical College Hospital, Chinese Academy of Medical Sciences and \\ Peking Union Medical College, Beijing 100042, China, \$Department of Anaesthesia and Intensive Care, The Chinese University of Hong Kong, \\ Hong Kong 999077, China and \$State Key Laboratory of Digestive Disease, LKS Institute of Health Sciences, The Chinese University of Hong \\ Kong, Hong Kong 999077, China
}

Received 3 January 2016; revision accepted 3 February 2016

\begin{abstract}
Long non-coding RNAs (lncRNAs) compose a group of non-protein-coding RNAs - more than 200 nucleotides in length. Recent studies have shown that IncRNAs play important roles in different cellular processes, including proliferation, differentiation, migration and invasion. Deregulation of lncRNAs has been widely reported in human tumours, in which they are able to function as either oncogenes (on the one hand) or tumour suppressor genes (on the other). Deregulation of CCAT1 (colon cancer-associated transcript-1), an oncogenic IncRNA, has been documented in different types of malignancy, such as gastric cancer, colorectal cancer and hepatocellular carcinoma. In this regard, enforced expression of CCAT1 exerts potent tumorigenic effects by promoting cell proliferation, invasion and migration. Recent evidence has also shown that CCAT1 may serve as a prognostic cancer biomarker. In this review, we provide an overview of current evidence relating to the role and biological function of CCAT1 in tumour development.
\end{abstract}

\section{Introduction}

Long non-coding RNAs (lncRNAs) consist of a group of non-coding RNAs with more than 200 nucleotides in length (1-4). These RNAs demonstrate limited proteincoding potential but could regulate gene expression transcriptionally and post-transcriptionally (5-7). Deregulation

Correspondence: Jianxiong Shen, Department of Orthopedics Surgery, Peking Union Medical College Hospital, Chinese Academy of Medical Sciences and Peking Union Medical College, Beijing 100042, China. Tel.: +86010 69152812; Fax: +86010 69152812; E-mail: shenjianxiong@medmail.com.cn

$\mathrm{Xin} \mathrm{Yu}$ and $\mathrm{Zheng} \mathrm{Li}$ contributed equally to this work. of lncRNAs has been observed in a variety of human diseases, including cancer (8-10). The functional involvement of lncRNAs in tumorigenesis has received much attention over the past decade (11-13). Pertinent to clinical practice, deregulation of IncRNAs in many cancer types has been associated with clinicopathological parameters, including metastasis, patients' survival and recurrence $(6,14,15)$. IncRNA deregulation also contributes to cancer progression through abnormal regulation of genes involved in cancer-related cellular processes, including cell proliferation and invasion (12,16-24).

Colon cancer-associated transcript-1 (CCAT1) is a newly discovered lncRNA with 2628 base pairs in length (25-27). CCAT1 gene is located on chromosome $8 \mathrm{q} 24.21$ and in the vicinity of c-MYC, a well-known transcription factor $(25,28)$. CCAT1 was first found to be upregulated in colon cancer (29). Recently, CCAT1 was found to be consistently deregulated in various cancer types $(27,30,31)$. The location of CCAT1 gene on chromosome $8 \mathrm{q} 24.21$ is crucial as this area is a "hot spot' harbouring multiple genetic alternations in both colon and prostate cancers (32).

CCAT1 is an enhancer-derived RNAs transcribed from a distal enhancer $515 \mathrm{~kb}$ upstream of the c-MYC gene (Fig. 1) (33,34). CCAT1 contains two exons and a poly-A tail and is mainly expressed in the nucleus. In colon cancer cells, CCAT1 is localized at its site of transcription $(26,29)$, which is important for mediating the long-range chromatin interactions between CCATl gene and $c-M Y C$ in conjunction with an enhancer $335 \mathrm{~kb}$ upstream of $c-M Y C$. In this manner, CCAT1 transcriptionally activates c-MYC in a cis-acting manner. Depletion of CCAT-1 could, therefore, reduce the transcription of $\mathrm{c}-M Y C$ gene.

In this review, we discuss the roles of CCAT1 as one of the most important regulatory RNAs in human cancer in relation to its deregulation, molecular functions and clinical significance (Table 1). 
(a) Chromosome bands
Contigs Genes

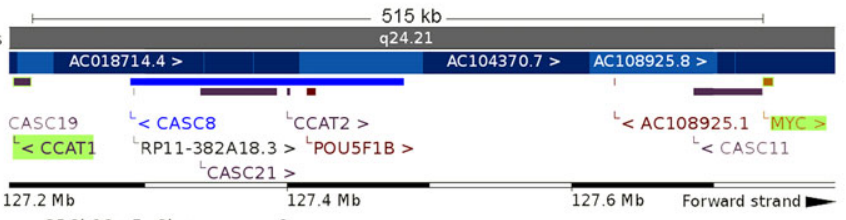

(b)

GRCh38.p5 Chromosome 8

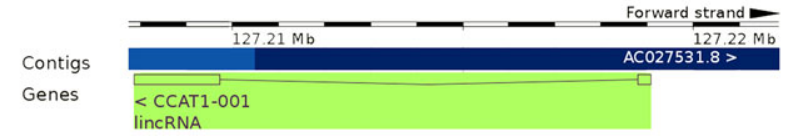

Figure 1. CCAT1 is an enhancer-derived RNAs transcribed from a distal enhancer $515 \mathrm{~kb}$ upstream of the c-MYC gene.

\section{Colorectal cancer}

Colorectal cancer is a common malignancy with around 1.2 million newly diagnosed cases worldwide each year (35-37). Its mortality rate is the third highest among all cancers, leading to approximately 0.6 million deaths annually $(36,38,39)$. Currently, CEA and CA19-9 are the two most frequently used clinical diagnostic biomarkers (40-42). However, they have little significance in early diagnosis of colorectal cancer because of their lack of sensitivity and specificity. Identification, validation and clinical application of novel colorectal cancer-specific biomarkers may, therefore, improve the diagnostic accuracy, staging, patient follow-up and treatment selection of this prevalent disease.

Nissan et al. demonstrated that the expression level of CCAT1 was significantly upregulated in colon adenocarcinoma as compared with healthy controls (29). The expression of CCAT1 was significantly increased in both the early and late stages of colon cancer. CCAT1 was also strongly expressed in adenomatous polyps, tumour-proximal colonic epithelium, liver metastasis and the associated lymph nodes. Pertinent to non-invasive diagnosis, CCAT1 overexpression was detectable in $40 \%$ of peripheral blood samples of colorectal cancer patients, while it was largely undetectable in healthy controls. Alaiyan et al. also identified significant upregulation of CCAT1 in both pre-malignant and malignant lesions of the colon, including adenomatous polyps, primary tumour tissue, normal mucosa adjacent to primary tumour and lymph node, liver and peritoneal metastases (27).

In relation to prognostication, Ye et al. showed that the expression level of CCAT1 was significantly correlated with tumour staging, local infiltration depth, vascular invasion and CA19-9 level (43). CCAT1 also predicted the sensitivity of colon cancer cells to bromodomain and extraterminal (BET) inhibition, which preferentially reduced the growth of colon cancer with the $\mathrm{CpG}$ island methylator phenotype. In this regard, CCAT1 was sensitive to BET inhibition, correlated with c-MYC transcript and cell growth, and proposed to be a biomarker for selecting patients who are most likely to benefit from BET inhibitors (44). Another study investigated the diagnostic ability of a CCAT1-specific peptide nucleic acidbased molecular beacon (CCAT1 TO-PNA-MB) for detection of colorectal cancer (26). The data showed that CCAT1 TO-PNA-MB could serve as a diagnostic tool for colorectal cancer in vitro, ex vivo and in situ (human colon biopsies). Hybridization of TO-PNA-MB could detect CCAT1 expression in all (4/4) human colon biopsies with pre-cancerous adenomas, as well as in all (8/8) patients with invasive adenocarcinoma (penetrating the bowel wall). He et al. (45) further demonstrated that c-Myc could reciprocally increase CCAT1 expression through binding to its promoter region while overexpression of CCAT1 promoted colon cancer cell proliferation and

Table 1. Functional characterization of the CCAT1 in tumours

\begin{tabular}{|c|c|c|c|c|c|}
\hline Cancer types & Expression & Phenotypes affected & Related gene & Role & References \\
\hline Colorectal cancer & Upregulated & Proliferation, invasion & c-Myc & Oncogenic & $(26,27,29,43-45)$ \\
\hline Gastric cancer & Upregulated & Proliferation, invasion & c-Myc, ERK/MAPK & Oncogenic & $(25,52,53)$ \\
\hline Hepatocellular carcinoma & Upregulated & Proliferation, migration & let-7, HMGA2, c-Myc & Oncogenic & $(28,30,65)$ \\
\hline Gallbladder cancer & Upregulated & Proliferation, invasion & Bmi1, miR-218-5p & Oncogenic & (69) \\
\hline Ovarian cancer & Upregulated & Metastasis & & Oncogenic & (77) \\
\hline Breast cancer & Upregulated & & & Oncogenic & (31) \\
\hline Lung cancer & Upregulated & Proliferation & & Oncogenic & $(78,80)$ \\
\hline
\end{tabular}


invasion. To conclude, CCAT1 is a highly specific and readily detectable diagnostic biomarker for colorectal cancer, in which its upregulation contributes to both tumour growth and metastasis.

\section{Gastric cancer}

Gastric cancer is the fourth most frequent cancer and the second leading cause of cancer-related death worldwide (46-49). Although Helicobacter pylori and Epstein-Barr virus are two major aetiological factors of gastric cancer, our understanding of its molecular mechanisms remains largely incomplete (50-52). It is, therefore, crucial to identify novel molecular abnormalities in this deadly disease.

CCAT1 was upregulated in gastric carcinoma tissues compared with normal tissues $(53,54)$. Similar to colorectal cancer, the transcription factor c-Myc increased the expression of CCAT1 by directly binding to its promoter region (25). The expression level of CCAT1 was correlated with cancer growth, lymph node metastasis and distal metastatic disease in gastric cancer. Moreover, CCAT1 promoted gastric cancer cell proliferation and migration in vitro. Mizrahi et al. also demonstrated that the expression level of CCAT1 was significantly higher in gastric cancer samples than that in the control group. In addition, CCAT1 expression was elevated in human gastric carcinoma cell lines. The expression levels of CCAT1 were found to be highest in tissues from recurrent gastric cancer cases (53). In conclusion, expression of CCAT1 is increased in gastric cancer, in which it serves as a potential marker for metastatic disease. Functionally, CCAT1 acts as an oncogene in gastric cancer, suggesting its potential utilization as a therapeutic target.

\section{Hepatocellular carcinoma}

Hepatocellular carcinoma (HCC) is the fifth most frequent solid tumour and the third leading cause of cancer deaths worldwide (55-58). Chronic infection with either hepatitis $\mathrm{B}$ or $\mathrm{C}$ virus plays significant roles in the development of HCC (59-61). Despite recent advances in surgery and medical treatment, the prognosis of $\mathrm{HCC}$ patients remains extremely poor (62-64). Therefore, it is crucial to understand the pathogenesis of HCC.

The expression level of CCAT1 was significantly elevated in HCC tissues compared with matched noncancerous hepatic tissues $(28,30,65)$. In addition, the expression level of CCAT1 predicted poor prognosis in HCC, correlated with tumour size, microvascular invasion and alpha foetal protein (AFP) expression. Furthermore, CCAT1 promoted the proliferation and migration of HCC cells in vitro through binding and antagonizing let-7, a tumour-suppressive microRNA, and thereby

(C) 2016 John Wiley \& Sons Ltd derepressing the expression of let-7 targets HMGA2 and c-Myc. Taken together, CCAT1 is involved in the development and progression of $\mathrm{HCC}$ via functioning as a let-7 sponge. CCAT1 might act as an oncogene in HCC, suggesting its potential utilities as a prognostic marker and a therapeutic target.

\section{Gallbladder cancer}

Gallbladder cancer is fifth most frequent gastrointestinal malignancy (66-69). The pathogenesis of gallbladder carcinoma remains largely unknown. Therefore, it is of great importance to study its molecular mechanisms.

The expression of CCAT1 was higher in gallbladder cancer tissues compared with adjacent normal tissues (70). In addition, CCAT1 overexpression increased the expression of Bmil, which is the target gene of miRNA218-5p. Further analysis showed that CCAT1 knockdown inhibited the proliferation and invasiveness of gallbladder cancer cells, at least in part, through regulation of Bmil. In this regard, transcript level of CCAT1 was correlated with Bmil in gallbladder cancer tissues. In conclusion, CCAT1 functions as an oncogenic lncRNA in gallbladder cancer in part through sponging miRNA-218-5p.

\section{Ovarian cancer}

Ovarian cancer is the most lethal gynaecological cancer and the fifth leading cause of cancer-related death (7174). There has been no improvement in its mortality rate over the last 20 years (75-77). Much attention has, therefore, been given to the pathogenic mechanisms, particularly pathways that regulate metastasis of ovarian cancer.

Compared with the parental SKOV 3 cells, the invasive ability of the SKOV3.ip1 cell line was significantly higher (78). Among 4956 detected lncRNAs in SKOV3.ip1 cells, the expression levels of 583 lncRNAs were upregulated and the expression levels of 578 were downregulated as compared with SKOV3 cells by microarray. Moreover, reverse transcription-quantitative PCR confirmed the deregulation of seven analysed lncRNAs (MALAT1, H19, UCA1, CCAT1, LOC645249, LOC100128881 and LOC100292680). These findings implicated that CCAT1 might play a role in ovarian cancer metastasis. Further studies are needed to determine the exact role of CCAT1 in ovarian cancer.

\section{Breast cancer}

Zhang et al. (31) demonstrated that the expression of CCAT1 was upregulated in breast cancer tissues compared with the adjacent normal tissues. The high 
expression of CCAT1 was correlated with tumournode-metastasis (TNM) staging, differentiation grade and lymph node metastases. Patients with high CCAT1 expression had a poor overall and progression-free survival. These results suggested that CCAT1 might function as an oncogenic lncRNA and serve as a potential prognostic marker in breast cancer.

\section{Lung cancer}

White et al. (79) depicted the landscape of lncRNA deregulation in lung cancer by integrative analysis of publicly available transcriptome sequencing data from 567 lung adenocarcinoma and squamous cell carcinoma tumours. By comparison with matched control, the authors identified 111 differentially expressed lncRNAs, including CCAT1. In a subsequent study, the same group demonstrated that knockdown of CCAT1 could potently inhibit lung cancer cell proliferation (80).

\section{Conclusion}

CCAT1 is a relatively well-characterized oncogenic IncRNA, which is upregulated in many types of cancer, including colorectal cancer, gastric cancer, HCC, gallbladder cancer, ovarian cancer, breast cancer and lung cancer. Functional characterization has also demonstrated that CCAT1 could promote tumour cell proliferation, migration and invasion. Although the involvement of c-Myc in the oncogenic function of CCAT1 has been demonstrated, its detailed upstream and downstream molecular mechanisms remain to be systematically studied. Pertinent to clinical utility, the overexpression of CCAT1 is very often associated with poor clinical outcomes. Therefore, this IncRNA may serve a prognostic biomarker. With more efforts being put forth to the study of IncRNAs especially CCAT1, it is hopeful that CCAT1 will obtain routine clinical utility at last.

\section{Acknowledgements}

This work was supported by grants from the National Natural Science Foundation of China (NSFC) (grant number 81401847).

\section{Conflict of interest}

The authors declare no conflict of interest.

\section{References}

1 Yu X, Li Z (2015) Long non-coding RNA HOTAIR: a novel oncogene (Review). Mol. Med. Rep. 12, 5611-5618. doi:10.3892/ mmr.2015.4161.
2 Yu X, Li Z (2015) Long non-coding RNA growth arrest-specific transcript 5 in tumor biology. Oncol. Lett. 10, 1953-1958. doi:10.3892/ol.2015.3553.

3 Wan X, Ding X, Chen S, Song H, Jiang H, Fang Y et al. (2015) The functional sites of miRNAs and lncRNAs in gastric carcinogenesis. Tumour Biol. 36, 521-532. doi:10.1007/s13277-015-3136-5.

$4 \mathrm{Hu}$ X, Bao J, Wang Z, Zhang Z, Gu P, Tao F et al. (2015) The plasma lncRNA acting as fingerprint in non-small-cell lung cancer. Tumour Biol. [Epub ahead of print]. doi:10.1007/s13277-015-40239.

5 Tano K, Akimitsu N (2012) Long non-coding RNAs in cancer progression. Front. Genet. 3, 219. doi:10.3389/fgene.2012.00219.

6 Cai X, Liu Y, Yang W, Xia Y, Yang C, Yang S et al. (2015) Long noncoding RNA MALAT1 as a potential therapeutic target in osteosarcoma. J. Orthop. Res. [Epub ahead of print]. doi:10.1002/ jor.23105.

7 Zhou X, Liu S, Cai G, Kong L, Zhang T, Ren Y et al. (2015) Long Non Coding RNA MALAT1 Promotes Tumor Growth and Metastasis by inducing Epithelial-Mesenchymal Transition in Oral Squamous Cell Carcinoma. Sci. Rep. 5, 15972. doi:10.1038/ srep15972.

8 Iranpour M, Soudyab M, Geranpayeh L, Mirfakhraie R, Azargashb E, Movafagh A et al. (2015) Expression analysis of four long noncoding RNAs in breast cancer. Tumour Biol. [Epub ahead of print]. doi:10.1007/s13277-015-4135-2.

9 Zhang M, Gu H, Xu W, Zhou X (2015) Down-regulation of lncRNA MALAT1 reduces cardiomyocyte apoptosis and improves left ventricular function in diabetic rats. Int. J. Cardiol. 203, 214 216. doi:10.1016/j.ijcard.2015.10.136.

10 Zhang M, Gu H, Chen J, Zhou X (2016) Involvement of long noncoding RNA MALAT1 in the pathogenesis of diabetic cardiomyopathy. Int. J. Cardiol. 202, 753-755. doi:10.1016/j.ijcard. 2015.10.019.

11 Yoshimoto R, Mayeda A, Yoshida M, Nakagawa S (2016) MALAT1 long non-coding RNA in cancer. Biochim. Biophys. Acta 1859, 192-199. doi:10.1016/j.bbagrm.2015.09.012.

12 Wang D, Ding L, Wang L, Zhao Y, Sun Z, Karnes RJ et al. (2015) LncRNA MALAT1 enhances oncogenic activities of EZH2 in castration-resistant prostate cancer. Oncotarget 6, 41045-41055. doi:10.18632/oncotarget.5728.

13 Liu Q, Huang J, Zhou N, Zhang Z, Zhang A, Lu Z et al. (2013) LncRNA loc285194 is a p53-regulated tumor suppressor. Nucleic Acids Res. 41, 4976-4987. doi:10.1093/nar/gkt182.

14 Cao X, Zhao R, Chen Q, Zhao Y, Zhang B, Zhang Y et al. (2015) MALAT1 might be a predictive marker of poor prognosis in patients who underwent radical resection of middle thoracic esophageal squamous cell carcinoma. Cancer Biomark. 15, 717-723. doi:10.3233/CBM-150513

15 Nie FQ, Sun M, Yang JS, Xie M, Xu TP, Xia R et al. (2015) Long noncoding RNA ANRIL promotes non-small cell lung cancer cell proliferation and inhibits apoptosis by silencing KLF2 and P21 expression. Mol. Cancer Ther. 14, 268-277. doi:10.1158/15357163.MCT-14-0492.

16 Konishi H, Ichikawa D, Yamamoto Y, Arita T, Shoda K, Hiramoto $\mathrm{H}$ et al. (2016) Plasma MALAT1 Level Is Associated with Liver Damage and Predicts Development of Hepatocellular Carcinoma. Cancer Sci. 107, 149-154. doi:10.1111/cas. 12854.

17 Yang L, Bai HS, Deng Y, Fan L (2015) High MALAT1 expression predicts a poor prognosis of cervical cancer and promotes cancer cell growth and invasion. Eur. Rev. Med. Pharmacol. Sci. 19, 3187-3193.

18 Jin C, Yan B, Lu Q, Lin Y, Ma L (2015) The role of MALAT1/ miR-1/slug axis on radioresistance in nasopharyngeal carcinoma. 
Tumour Biol. [Epub ahead of print]. doi:10.1007/s13277-015-4227$\mathrm{z}$.

19 Tian X, Xu G (2015) Clinical value of lncRNA MALAT1 as a prognostic marker in human cancer: systematic review and metaanalysis. BMJ Open 5, e008653. doi:10.1136/bmjopen-2015008653.

20 Lu H, He Y, Lin L, Qi Z, Ma L, Li L et al. (2015) Long non-coding RNA MALAT1 modulates radiosensitivity of HR-HPV+ cervical cancer via sponging miR-145. Tumour Biol. [Epub ahead of print]. doi:10.1007/s13277-015-3946-5.

21 Wei Y, Niu B (2015) Role of MALAT1 as a Prognostic factor for survival in various cancers: a systematic review of the literature with meta-analysis. Dis. Markers 2015, 164635. doi:10.1155/2015/ 164635.

22 Wan Y, Chang HY (2010) HOTAIR: Flight of noncoding RNAs in cancer metastasis. Cell Cycle 9, 3391-3392.

23 Gupta RA, Shah N, Wang KC, Kim J, Horlings HM, Wong DJ et al. (2010) Long non-coding RNA HOTAIR reprograms chromatin state to promote cancer metastasis. Nature 464, 1071-1076. doi:10.1038/nature08975.

24 Kogo R, Shimamura T, Mimori K, Kawahara K, Imoto S, Sudo T et al. (2011) Long noncoding RNA HOTAIR regulates polycombdependent chromatin modification and is associated with poor prognosis in colorectal cancers. Cancer Res. 71, 6320-6326. doi:10.1158/0008-5472.CAN-11-1021.

25 Yang F, Xue X, Bi J, Zheng L, Zhi K, Gu Y et al. (2013) Long noncoding RNA CCAT1, which could be activated by c-Myc, promotes the progression of gastric carcinoma. J. Cancer Res. Clin. Oncol. 139, 437-445. doi:10.1007/s00432-012-1324-X.

26 Kam Y, Rubinstein A, Naik S, Djavsarov I, Halle D, Ariel I et al. (2014) Detection of a long non-coding RNA (CCAT1) in living cells and human adenocarcinoma of colon tissues using FIT-PNA molecular beacons. Cancer Lett. 352, 90-96. doi:10.1016/j.canlet.2013.02.014.

27 Alaiyan B, Ilyayev N, Stojadinovic A, Izadjoo M, Roistacher M, Pavlov V et al. (2013) Differential expression of colon cancer associated transcript1 (CCAT1) along the colonic adenoma-carcinoma sequence. BMC Cancer 13, 196. doi:10.1186/1471-2407-13196.

28 Zhu HQ, Zhou X, Chang H, Li HG, Liu FF, Ma CQ et al. (2015) Aberrant Expression of CCAT1 regulated by c-Myc Predicts the Prognosis of Hepatocellular Carcinoma. Asian Pac. J. Cancer Prev. 16, 5181-5185.

29 Nissan A, Stojadinovic A, Mitrani-Rosenbaum S, Halle D, Grinbaum R, Roistacher M et al. (2012) Colon cancer associated transcript-1: a novel RNA expressed in malignant and pre-malignant human tissues. Int. J. Cancer 130, 1598-1606. doi:10.1002/ ijc. 26170 .

30 Deng L, Yang SB, Xu FF, Zhang JH (2015) Long noncoding RNA CCAT1 promotes hepatocellular carcinoma progression by functioning as let-7 sponge. J. Exp. Clin. Cancer Res. 34, 18. doi:10.1186/s13046-015-0136-7.

31 Zhang XF, Liu T, Li Y, Li S (2015) Overexpression of long noncoding RNA CCAT1 is a novel biomarker of poor prognosis in patients with breast cancer. Int. J. Clin. Exp. Pathol. 8, 9440-9445.

32 Chung CC, Hsing AW, Edward Y, Biritwum R, Tettey Y, Adjei A et al. (2014) A comprehensive resequence-analysis of $250 \mathrm{~kb}$ region of $8 \mathrm{q} 24.21$ in men of African ancestry. Prostate 74, 579589.

33 Xiang JF, Yin QF, Chen T, Zhang Y, Zhang XO, Wu Z et al. (2014) Human colorectal cancer-specific CCAT1-L lncRNA regulates long-range chromatin interactions at the MYC locus. Cell Res. 24, 513-531. doi:10.1038/cr.2014.35.
34 Younger ST, Rinn JL (2014) 'Lnc'-ing enhancers to MYC regulation. Cell Res. 24, 643-644. doi:10.1038/cr.2014.54.

35 Yu X, Li Z, Yu J, Chan MT, Wu WK (2015) MicroRNAs predict and modulate responses to chemotherapy in colorectal cancer. Cell Prolif. 48, 503-510. doi:10.1111/cpr.12202.

36 Zhang J, Lu Y, Yue X, Li H, Luo X, Wang Y et al. (2013) MiR124 suppresses growth of human colorectal cancer by inhibiting STAT3. PLoS ONE 8, e70300. doi:10.1371/journal.pone.0070300.

37 Lim L, Balakrishnan A, Huskey N, Jones KD, Jodari M, Ng R et al. (2014) MicroRNA-494 within an oncogenic microRNA megacluster regulates G1/S transition in liver tumorigenesis through suppression of mutated in colorectal cancer. Hepatology 59, 202-215. doi:10.1002/hep.26662.

38 Liu L, Nie J, Chen L, Dong G, Du X, Wu X et al. (2013) The oncogenic role of microRNA-130a/301a/454 in human colorectal cancer via targeting Smad4 expression. PLOS ONE 8, e55532. doi:10.1371/journal.pone.0055532.

39 Yang $\mathrm{MH}$, Yu J, Chen N, Wang XY, Liu XY, Wang S et al. (2013) Elevated microRNA-31 expression regulates colorectal cancer progression by repressing its target gene SATB2. PLOS ONE 8, e85353. doi:10.1371/journal.pone.0085353.

40 Hu B, Ren D, Su D, Lin H, Xian Z, Wan X et al. (2012) Expression of the phosphorylated MEK5 protein is associated with TNM staging of colorectal cancer. BMC Cancer 12, 127. doi:10.1186/ 1471-2407-12-127.

41 Wang RF, Song BR, Peng JJ, Cai GX, Liu FQ, Wang MH et al. (2014) The Prognostic Value of Preoperative Serum CEA and CA19-9 Values in Stage I-III Colorectal Cancer. Hepatogastroenterology 61, 994-999.

42 Christensen IJ, Brunner N, Dowell B, Davis G, Nielsen HJ, Newstead G et al. (2015) Plasma TIMP-1 and CEA as Markers for Detection of Primary Colorectal Cancer: A Prospective Validation Study Including Symptomatic and Non-symptomatic Individuals. Anticancer Res. 35, 4935-4941.

43 Ye Z, Zhou M, Tian B, Wu B, Li J (2015) Expression of lncRNACCAT1, E-cadherin and N-cadherin in colorectal cancer and its clinical significance. Int. J. Clin. Exp. Med. 8, 3707-3715.

44 McCleland ML, Mesh K, Lorenzana E, Chopra VS, Segal E, Watanabe C et al. (2016) CCAT1 is an enhancer-templated RNA that predicts BET sensitivity in colorectal cancer. J. Clin. Investig. 126, 639-652. doi:10.1172/JCI83265.

45 He X, Tan X, Wang X, Jin H, Liu L, Ma L et al. (2014) C-Mycactivated long noncoding RNA CCAT1 promotes colon cancer cell proliferation and invasion. Tumour Biol. 35, 12181-12188. doi:10.1007/s13277-014-2526-4.

46 Li Z, Yu X, Wang Y, Shen J, Wu WK, Liang J et al. (2015) By downregulating TIAM1 expression, microRNA-329 suppresses gastric cancer invasion and growth. Oncotarget 6, 17559-17569.

47 Li Z, Lei H, Luo M, Wang Y, Dong L, Ma Y et al. (2015) DNA methylation downregulated mir-10b acts as a tumor suppressor in gastric cancer. Gastric Cancer 18, 43-54. doi:10.1007/s10120-0140340-8.

48 Shen X, Si Y, Yang Z, Wang Q, Yuan J, Zhang X (2015) MicroRNA-542-3p suppresses cell growth of gastric cancer cells via targeting oncogene astrocyte-elevated gene-1. Med. Oncol. 32, 361. doi:10.1007/s12032-014-0361-5.

49 Zuo QF, Zhang R, Li BS, Zhao YL, Zhuang Y, Yu T et al. (2015) MicroRNA-141 inhibits tumor growth and metastasis in gastric cancer by directly targeting transcriptional co-activator with PDZbinding motif, TAZ. Cell Death Dis. 6, e1623. doi:10.1038/cddis.2014.573.

50 Oh HK, Tan AL, Das K, Ooi CH, Deng NT, Tan IB et al. (2011) Genomic loss of miR-486 regulates tumor progression and the 
OLFM4 antiapoptotic factor in gastric cancer. Clin. Cancer Res. 17, 2657-2667. doi:10.1158/1078-0432.CCR-10-3152.

51 Zhang T, Wang Q, Zhao D, Cui Y, Cao B, Guo L et al. (2011) The oncogenetic role of microRNA-31 as a potential biomarker in oesophageal squamous cell carcinoma. Clin. Sci. (Lond.) 121, 437 447. doi:10.1042/CS20110207.

52 Xiao B, Guo J, Miao Y, Jiang Z, Huan R, Zhang Y et al. (2009) Detection of miR-106a in gastric carcinoma and its clinical significance. Clin. Chim. Acta 400, 97-102. doi:10.1016/j.cca.2008.10. 021.

53 Mizrahi I, Mazeh H, Grinbaum R, Beglaibter N, Wilschanski M, Pavlov V et al. (2015) Colon Cancer Associated Transcript-1 (CCAT1) Expression in Adenocarcinoma of the Stomach. J. Cancer 6, 105-110. doi:10.7150/jca.10568.

54 Zhang Y, Ma M, Liu W, Ding W, Yu H (2014) Enhanced expression of long noncoding RNA CARLo-5 is associated with the development of gastric cancer. Int. J. Clin. Exp. Pathol. 7, 8471-8479.

55 Chu YH, Hsieh MJ, Chiou HL, Liou YS, Yang CC, Yang SF et al. (2014) MicroRNA gene polymorphisms and environmental factors increase patient susceptibility to hepatocellular carcinoma. PLOS ONE 9, e89930. doi:10.1371/journal.pone.0089930.

56 Furuta M, Kozaki K, Tanimoto K, Tanaka S, Arii S, Shimamura T et al. (2013) The tumor-suppressive miR-497-195 cluster targets multiple cell-cycle regulators in hepatocellular carcinoma. PLoS ONE 8, e60155. doi:10.1371/journal.pone.0060155.

57 Hung TM, Ho CM, Liu YC, Lee JL, Liao YR, Wu YM et al. (2014) Up-regulation of microRNA-190b plays a role for decreased IGF-1 that induces insulin resistance in human hepatocellular carcinoma. PLOS ONE 9, e89446. doi:10.1371/journal.pone.0089446.

58 Wang SC, Lin XL, Li J, Zhang TT, Wang HY, Shi JW et al. (2014) MicroRNA-122 triggers mesenchymal-epithelial transition and suppresses hepatocellular carcinoma cell motility and invasion by targeting RhoA. PLOS ONE 9, e101330. doi:10.1371/journal.pone. 0101330 .

59 Huang S, Xie Y, Yang P, Chen P, Zhang L (2014) HCV core protein-induced down-regulation of microRNA-152 promoted aberrant proliferation by regulating Wnt1 in HepG2 cells. PLOS ONE 9, e81730. doi:10.1371/journal.pone.0081730.

60 Peng F, Xiao X, Jiang Y, Luo K, Tian Y, Peng M et al. (2014) HBx down-regulated Gld2 plays a critical role in HBV-related dysregulation of miR-122. PLOS ONE 9, e92998. doi:10.1371/journal.pone.0092998.

61 Tan Y, Ge G, Pan T, Wen D, Chen L, Yu X et al. (2014) A Serum MicroRNA Panel as Potential Biomarkers for Hepatocellular Carcinoma Related with Hepatitis B Virus. PLOS ONE 9, e107986. doi:10.1371/journal.pone.0107986.

62 Yu L, Ding GF, He C, Sun L, Jiang Y, Zhu L (2014) MicroRNA424 is down-regulated in hepatocellular carcinoma and suppresses cell migration and invasion through c-Myb. PLOS ONE 9, e91661. doi:10.1371/journal.pone.0091661.

63 Jung CJ, Iyengar S, Blahnik KR, Ajuha TP, Jiang JX, Farnham PJ et al. (2011) Epigenetic modulation of miR-122 facilitates human embryonic stem cell self-renewal and hepatocellular carcinoma proliferation. PLoS ONE 6, e27740. doi:10.1371/journal.pone.0027740.

64 Qiu X, Dong S, Qiao F, Lu S, Song Y, Lao Y et al. (2013) HBxmediated miR-21 upregulation represses tumor-suppressor function of PDCD4 in hepatocellular carcinoma. Oncogene 32, 3296-3305. doi:10.1038/onc.2013.150.

65 Zhu H, Zhou X, Chang H, Li H, Liu F, Ma C et al. (2015) CCAT1 promotes hepatocellular carcinoma cell proliferation and invasion. Int. J. Clin. Exp. Pathol. 8, 5427-5434.
66 Li Z, Yu X, Shen J, Law PT, Chan MT, Wu WK (2015) MicroRNA expression and its implications for diagnosis and therapy of gallbladder cancer. Oncotarget 6, 13914-13924.

67 Qiu Y, Luo X, Kan T, Zhang Y, Yu W, Wei Y et al. (2014) TGFbeta upregulates miR-182 expression to promote gallbladder cancer metastasis by targeting CADM1. Mol. BioSyst. 10, 679-685. doi:10.1039/c3mb70479c.

68 Ma MZ, Li CX, Zhang Y, Weng MZ, Zhang MD, Qin YY et al. (2014) Long non-coding RNA HOTAIR, a c-Myc activated driver of malignancy, negatively regulates miRNA-130a in gallbladder cancer. Mol. Cancer. 13, 156. doi:10.1186/14764598-13-156.

69 Chang Y, Liu C, Yang J, Liu G, Feng F, Tang J et al. (2013) MiR-20a triggers metastasis of gallbladder carcinoma. J. Hepatol. 59, 518-527. doi:10.1016/j.jhep.2013.04.034.

70 Ma MZ, Chu BF, Zhang Y, Weng MZ, Qin YY, Gong W et al. (2015) Long non-coding RNA CCAT1 promotes gallbladder cancer development via negative modulation of miRNA-218-5p. Cell Death Dis. 6, e1583. doi:10.1038/cddis.2014.541.

71 Creighton CJ, Hernandez-Herrera A, Jacobsen A, Levine DA, Mankoo P, Schultz N et al. (2012) Integrated analyses of microRNAs demonstrate their widespread influence on gene expression in high-grade serous ovarian carcinoma. PLoS ONE 7, e34546. doi:10.1371/journal.pone.0034546.

72 Yu X, Zhang X, Bi T, Ding Y, Zhao J, Wang C et al. (2013) MiRNA expression signature for potentially predicting the prognosis of ovarian serous carcinoma. Tumour Biol. 34, 3501-3508. doi:10.1007/s13277-013-0928-3.

73 Lee H, Park CS, Deftereos G, Morihara J, Stern JE, Hawes SE et al. (2012) MicroRNA expression in ovarian carcinoma and its correlation with clinicopathological features. World J Surg. Oncol. 10, 174. doi:10.1186/1477-7819-10-174.

74 Guo F, Cogdell D, Hu L, Yang D, Sood AK, Xue F et al. (2014) MiR-101 suppresses the epithelial-to-mesenchymal transition by targeting ZEB1 and ZEB2 in ovarian carcinoma. Oncol. Rep. 31, 2021-2028. doi:10.3892/or.2014.3106.

75 Chen X, Chen S, Xiu YL, Sun KX, Zong ZH, Zhao Y (2015) $\mathrm{RhoC}$ is a major target of microRNA-93-5P in epithelial ovarian carcinoma tumorigenesis and progression. Mol. Cancer. 14, 31. doi:10.1186/s12943-015-0304-6.

76 Liu Z, Gersbach E, Zhang X, Xu X, Dong R, Lee P et al. (2013) miR-106a represses the $\mathrm{Rb}$ tumor suppressor p130 to regulate cellular proliferation and differentiation in high-grade serous ovarian carcinoma. Mol. Cancer Res. 11, 1314-1325. doi:10.1158/15417786.MCR-13-0131.

77 Dai F, Zhang Y, Chen Y (2014) Involvement of miR-29b signaling in the sensitivity to chemotherapy in patients with ovarian carcinoma. Hum. Pathol. 45, 1285-1293. doi:10.1016/j.humpath.2014.02.008.

78 Liu SP, Yang JX, Cao DY, Shen K (2013) Identification of differentially expressed long non-coding RNAs in human ovarian cancer cells with different metastatic potentials. Cancer Biol. Med. 10, 138-141. doi:10.7497/j.issn.2095-3941.2013.03.003.

79 White NM, Cabanski CR, Silva-Fisher JM, Dang HX, Govindan R, Maher CA (2014) Transcriptome sequencing reveals altered long intergenic non-coding RNAs in lung cancer. Genome Biol. 15, 429. doi:10.1186/s13059-014-0429-8.

80 Cabanski CR, White NM, Dang HX, Silva-Fisher JM, Rauck CE, Cicka D et al. (2015) Pan-cancer transcriptome analysis reveals long noncoding RNAs with conserved function. RNA Biol. 12, 628-642. doi:10.1080/15476286.2015.1038012. 